\title{
Putting age-related hearing loss on the public health agenda in Australia
}

\author{
Kim M Kiely ${ }^{a, b, c, d}$ and Kaarin J Ansteya,b,c
}

a Ageing Futures Institute, UNSW, Sydney, Australia

b School of Psychology, UNSW, Sydney, Australia

c Neuroscience Research Australia (NeuRA), Sydney, NSW

d Corresponding author: k.kiely@unsw.edu.au

\section{Article history}

Publication date: 2 December 2021

Citation: Kiely KM, Anstey KJ. Putting agerelated hearing loss on the public health agenda in Australia. Public Health Res Pract. 2021;31(5):e3152125. https://doi. org/10.17061/phrp3152125

\section{Key points}

- Hearing loss is progressive, highly prevalent and a leading contributor to the nonfatal disease burden among older Australians

- Approximately one-third of adult-acquired hearing loss is preventable

- Modifiable risk factors include exposure to hazardous noise and ototoxic substances in occupational and recreational settings, certain medications, health behaviours, and chronic disease

- There is an urgent need to put in place a broad public health strategy to reduce the long-term disability burden attributable to hearing loss including targeted public health messaging, improved screening, and early detection

\section{Abstract}

Hearing loss is one of the most common long-term health conditions associated with ageing, and a considerable contributor to Australia's late-life disability burden. Acquired hearing loss in adulthood presents significant challenges for the social, physical, mental and cognitive health of many Australians. These wide-ranging individual and societal impacts have been highlighted by a number of high-profile national inquiries into Australia's hearing health during the past decade. Yet hearing loss remains poorly recognised and is undertreated in many communities. In this perspective article we argue that effective public health measures such as limiting occupational and recreational exposure to hazardous noise and ototoxic chemicals, promoting hearing health behaviours, early detection, improved access to hearing health services, and urban design, are all critical to mitigating these adverse outcomes. We also make the case for updated epidemiological data about hearing loss among older Australians.

\section{Introduction}

In 2017 there were an estimated 3.6 million Australians living with at least a mild degree of hearing loss, representing $14.5 \%$ of the population. More than three-quarters of these were people aged 60 years or older. ${ }^{1}$ By 2060 , the number of people with at least a mild hearing loss is projected to double to 7.8 million people; the chief driver being our ageing population. Nearly all adults experience progressive, irreversible and bilateral declines in hearing ability in later life ${ }^{2,3}$, which makes hearing loss one of the most common longterm health conditions associated with ageing. ${ }^{4,5}$

\section{Measuring hearing in the population}

Pure tone audiometry is the preferred standard for measuring hearing in the population. A hearing threshold is typically calculated from a pure tone average (PTA) of frequency tones between 500 and $4000 \mathrm{~Hz}$, the frequency range considered most relevant for speech processing. ${ }^{3}$ Using a PTA, a 
hearing impairment has been defined by thresholds greater than 25 decibels $(\mathrm{dB})$ in the better hearing ear ${ }^{5-7}$; this is the criteria on which the above Australia population estimates are based. More recently the World Health Organization (WHO) has been using thresholds greater than $20 \mathrm{~dB}$ to indicate hearing impairment. ${ }^{8}$ Importantly, there is wide variability in hearing trajectories over time (Figure 1), and also variability in the type, nature, and severity of impairment. When interpreting population estimates derived from a PTA, it is worth bearing in mind that some conditions such as central auditory dysfunction, tinnitus, and hidden hearing loss are not necessarily detected by pure tone audiometry. ${ }^{8}$ Similarly, criteria based solely on the better hearing ear will not identify all cases of unilateral impairment (asymmetrical hearing loss). On the other hand, although measures of self-reported hearing problems are also common in population research, they tend to underestimate the prevalence of hearing loss for older age groups. ${ }^{7}$

\section{Impacts of hearing loss}

For people who have lived with good hearing for most of their adult lives, an acquired hearing loss in later life has the potential to initiate a cascade of long-term outcomes that undermine quality of life and restrict independent living. These often start with difficulty understanding speech in noisy reverberant environments such as restaurants and other public venues. As hearing loss progresses to more moderate degrees of impairment (PTA >40 dB), communication difficulties are more likely to be encountered during normal conversation in quiet settings. ${ }^{3,8}$ Adults who are unable to effectively use strategies to overcome communication challenges posed by declining hearing may avoid, or be excluded from, situations that require effortful listening. It should therefore be of no surprise that untreated hearing loss is associated with lower levels of social engagement, lower rates of workforce participation, increased risk of social isolation, and poorer mental wellbeing. ${ }^{3,9}$

In addition to communication difficulties, it has long been recognised that hearing loss may have implications for a person's cognitive health and daily functioning. Many of the sequelae of untreated hearing loss are recognised risk factors for cognitive decline, and there is considerable evidence that hearing loss is an antecedent of cognitive impairment. This has led to hearing loss being proposed as a potentially modifiable risk factor for dementia in recent Lancet Commission articles about dementia prevention. ${ }^{10,11}$ Hearing loss has also been linked to reduced spatial awareness, balance problems and increased falls risk. ${ }^{8}$ Thus, many older adults with hearing loss, particularly when combined with other sensory and functional limitations, may limit their travel and have restricted life-space mobility. Comorbidities with hearing loss are common. Hearing loss may compound

Figure 1. Individual hearing trajectories measured using pure tone audiometry from a random sample of 1000 Australians aged 55 years and older

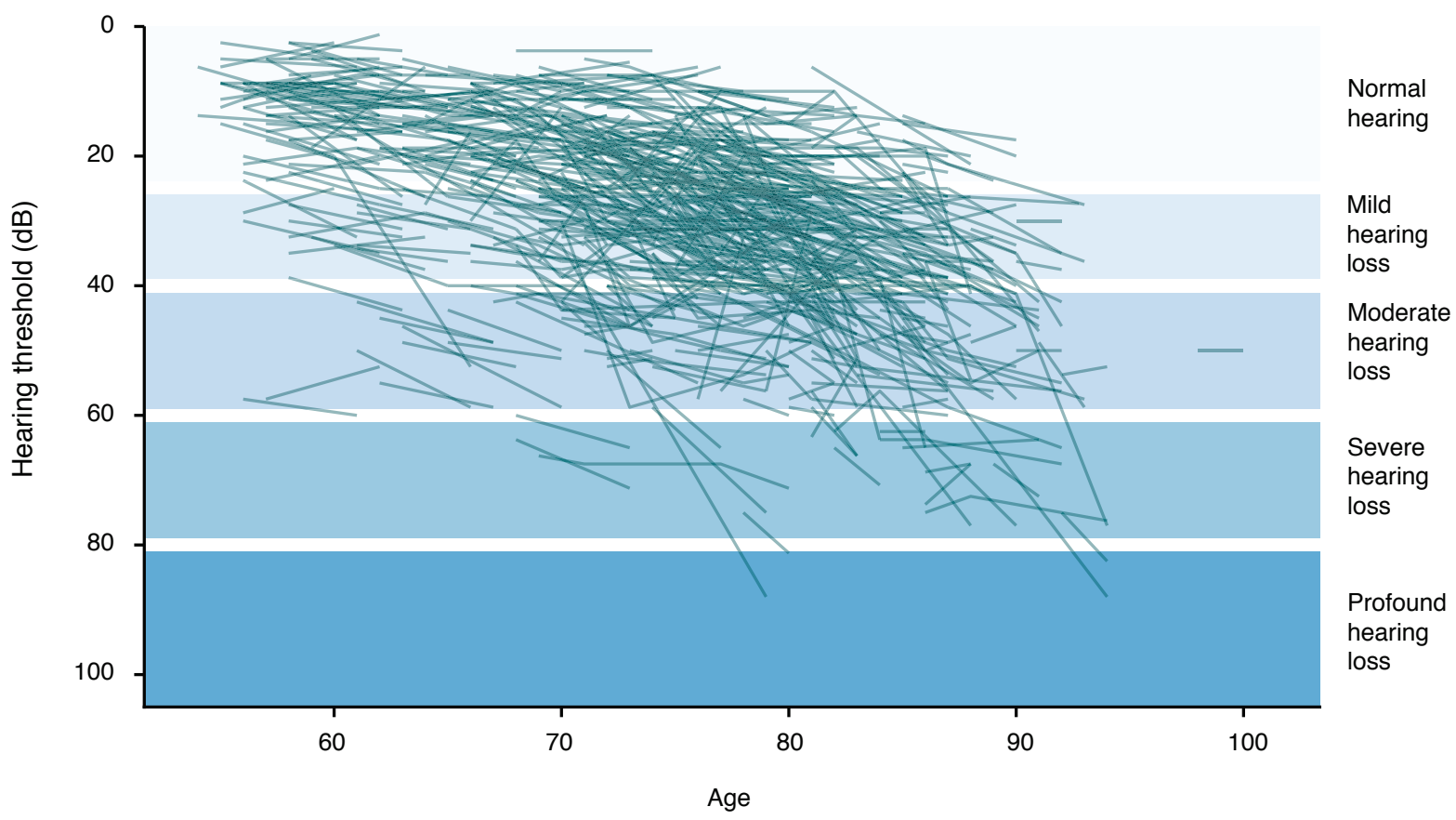

Note: Thresholds are calculated from a pure tone average (PTA) over frequency tones of 500, 1000, 2000, and 4000 $\mathrm{Hz}$ in the better hearing ear. A mild hearing loss is indicated within the range 26-40 decibels ( $\mathrm{dB})$, a moderate hearing loss within ranges $41-60 \mathrm{~dB}$, and severe to profound hearing loss in ranges above $61 \mathrm{~dB}$. Data from the DYNOPTA study 1992-2004. ${ }^{2}$ 
the impacts of other conditions by curbing help-seeking behaviour, and can be a barrier to accessing effective disease management and public health messages. ${ }^{3,4,8}$ The co-occurrence of hearing and vision loss, known as dual sensory loss, is especially debilitating because of the removal of an important compensatory mechanism for a single sensory loss. ${ }^{5}$ Similarly, sensory impairments have been shown to exacerbate challenges of living with dementia and may contribute to excess disability.

\section{Under-recognition and unmet need}

Because of its high prevalence and broad ranging impacts across multiple life domains, the Australian Burden of Disease study has ranked hearing loss among the foremost contributors to the nonfatal disease burden of older Australians. ${ }^{12}$ Yet age-related hearing impairment is often under-reported and poorly recognised in the wider community. The Royal Commission into Aged Care Quality and Safety found ageism to be one factor underlying poor service provision in aged care ${ }^{13}$ and it is likely that ageism similarly contributes to poor identification of hearing loss among older adults. Studies have found older adults with hearing loss identified by pure tone audiometry typically will not report concern about their hearing difficulties ${ }^{7}$ and many older adults are unaware of the services available to them. ${ }^{14}$ In addition, despite advances in hearing aid technologies, and hearing health professionals being well trained in how to best serve the hearing needs of an ageing population, there is low uptake of hearing aid devices by older adults with hearing loss, and hearing rehabilitation services are underused. 9,15 This unmet need is most acutely found in regional and rural areas, culturally and linguistically diverse communities, residential aged care, and areas of social disadvantage. ${ }^{14}$ This indicates a need for public campaigns to raise awareness of issues relating to hearing loss, and community interventions providing improved access to hearing services.

\section{Risk factors and prevention}

\section{targets}

The WHO estimates that approximately one-third of adult hearing loss is preventable. ${ }^{8}$ The main cause of preventable hearing loss is prolonged and frequent exposure to hazardous noise, most commonly in the workplace. Workers are most likely to be exposed to damaging noise in primary industry, construction, defence and the hospitality and entertainment industries. Recreational and other environmental noise are also significant causes of hearing loss, with younger cohorts particularly at risk.

Observance of workplace safety codes of practice addressing hazardous noise should lower the risk of noise-induced hearing loss ${ }^{16}$ but large numbers of Australians still work in noisy occupational settings. There has been no decline in the rate of successful workers' compensation claims for noise-induced hearing loss since 2001. Safe Work Australia argues that workers too often rely on personal protective equipment, which is easily misused or used infrequently. Ideally, environmental hazards should be controlled and isolated, if not removed entirely, to minimise levels of damaging exposure. ${ }^{14}$

The second major class of risk factors is ototoxic substances. These include many industrial chemicals, solvents, and heavy metals that are damaging to tissues of the inner ear and the vestibulocochlear nerve. There are also a number of occupations where workers are exposed to both hazardous noise and ototoxic substances, amplifying their risk of hearing loss. ${ }^{16,17}$ In addition, more than 150 common medications are known to be ototoxic, for example some antibiotics, cancer chemotherapeutic agents, quinine, and some anti-inflammatories. ${ }^{8,18}$ It is important for physicians to understand and consider the risks of hearing loss from use of these medications. ${ }^{18}$ Baseline screening and ongoing monitoring of hearing is critical in situations where it is not an option to prescribe alternative medications or a lower dose.

Other recognised risk factors for hearing loss include lifestyle behaviours such as smoking and health conditions such as hypertension, diabetes, and head trauma. $^{2}$

\section{Supporting people with hearing loss}

Early detection is critical to allow timely intervention to support adults with acquired hearing loss and improve their hearing health outcomes before many of the more disabling impacts eventuate. ${ }^{9,19}$ Hearing services are subsidised for eligible adults (for example, people with a pensioner concession card, held by more than 4 million Australians), and most audiology clinics offer low-cost (or free) initial hearing tests. General practice has also been identified as ideal for providing screening and referral to hearing services. ${ }^{9}$ There are also several reliable self-report screening instruments for hearing disability available for this purpose. The emergence of validated app-based screening tools will also enable initial screening for potential hearing loss to occur in a wider range of settings. ${ }^{20}$

Issues relating to the clinical management of agerelated hearing loss are beyond the scope of this commentary. Nevertheless, it is important to recognise that hearing aids are highly effective at improving the quality of life for successful users of any age. Although hearing aids should not be viewed as a panacea for managing hearing loss and may not be suitable for everyone, this is not a reason to withhold referral to hearing services. Hearing healthcare does not rely 
solely on provision of hearing aids; other options for rehabilitation and support are available. It is crucial that older adults, and people living with dementia or another impairment, are not excluded from hearing services because of their age, capacity, or functional limitations.

Urban, building, and interior design also have important roles to play in establishing environmental conditions that support people with hearing loss. Spaces with poor acoustics, hard surfaces, loud background noise, and low light conditions impeding visual cues for communication, are all examples of design characteristics that create challenging listening environments. ${ }^{21}$

\section{Better population data}

There is a lack of reliable contemporary population-based data on hearing health in Australia. National estimates of hearing loss and associated costs are based on data that are several decades old and not representative of currently ageing cohorts. ${ }^{1,6}$ This limits our public health capacity to identify, plan for, and respond to emerging hearing health challenges in future. Incorporating validated screening tools into existing or future cohort studies would allow a more accurate estimation of the population burden associated with hearing loss, and allow us to properly address current research priorities relating to inequalities in unmet need and to identify ways to improve access to hearing healthcare.

\section{Conclusion}

The annual cost of hearing loss in Australia is estimated to be approximately $\$ 33.3$ billion. ${ }^{1}$ In future, the number of Australians living with hearing loss is expected to increase as a direct result of population ageing. The anticipated individual and societal costs are substantial and have been well documented in numerous major national investigations. 1,14,15,19,22,23 To meet this challenge, there is an urgent need to put in place a broad public health strategy to reduce the long-term disability burden attributable to hearing loss. This should include a mix of prevention, public awareness campaigns, targeted education for medical and healthcare professionals, screening programs, and adoption of inclusive design principles. ${ }^{4}$

\section{Acknowledgements}

KA receives funding from an Australian Research Council Laureate Fellowship.

\section{Peer review and provenance}

Externally peer reviewed, invited.

\section{Competing interests}

None declared.

\section{Author contributions}

KK and KA drafted the manuscript and made critical revisions.

\section{References}

1. Deloitte Access Economics. The social and economic cost of hearing loss in Australia. Sydney: Hearing Care Industry Association; 2017 [cited 2021 Aug 9]. Available from: www.hcia.com.au/hcia-wp/wp-content/ uploads/2017/08/Social-and-Economic-Cost-of-HearingHealth-in-Australia_June-2017.pdf

2. Kiely KM, Gopinath B, Mitchell P, Luszcz M, Anstey KJ. Cognitive, health, and sociodemographic predictors of longitudinal decline in hearing acuity among older adults. J Gerontol A Biol Sci Med Sci. 2012;67(9):997-1003.

3. Gates GA, Mills JH. Presbycusis. Lancet. 2005;366(9491):1111-20.

4. Haile LM, Kamenov K, Briant PS, Orji AU, Steinmetz JD, Abdoli $A$, et al. Hearing loss prevalence and years lived with disability, 1990-2019; findings from the Global Burden of Disease Study 2019. Lancet. 2021;397(10278):996-1009.

5. Kiely KM, Mitchell P, Gopinath B, Luszcz MA, Jagger C, Anstey KJ. Estimating the years lived with and without age-related sensory impairment. J Gerontol A Biol Sci Med Sci. 2016;71(5):637-42.

6. Wilson DH, Walsh PG, Sanchez L, Davis AC, Taylor AW, Tucker G, Meagher I. The epidemiology of hearing impairment in an Australian adult population. Int $\mathrm{J}$ Epidemiol. 1999;28(2):247-52.

7. Kiely KM, Gopinath B, Mitchell P, Browning CJ, Anstey KJ. Evaluating a dichotomized measure of selfreported hearing loss against gold standard audiometry: prevalence estimates and age bias in a pooled national dataset. J Aging Health. 2012;24(3):439-58.

8. World Health Organization. World report on hearing. Geneva: WHO; 2021 [cited 2021 Aug 9]. Available from: www.who.int/publications/i/item/world-report-on-hearing

9. McMahon CM, Gopinath B, Schneider J, Reath J, Hickson L, Leeder SR, et al. The need for improved detection and management of adult-onset hearing loss in Australia. Int J Otolaryngol. 2013:1-7.

10. Livingston G, Sommerlad A, Orgeta V, Costafreda SG, Huntley J, Ames D, et al. Dementia prevention, intervention, and care. Lancet. 2017;390:2673-734.

11. Livingston G, Huntley J, Sommerlad A, Ames D, Ballard C, Banerjee S, et al. Dementia prevention, intervention, and care: 2020 report of the Lancet Commission. Lancet. 2020;396(10248):413-46. 
12. Australian Institute of Health and Welfare. Australian burden of disease study: impact and causes of illness and death in Australia 2011. Canberra: AlHW; 2016 [cited 2021 Aug 9]. Available from: www.aihw.gov.au/ reports/burden-of-disease/burden-disease-study-illnessdeath-2015/summary

13. Royal Commission into Aged Care Quality and Safety. Final report: care, dignity and respect. Canberra: Commonwealth of Australia; 2021 [cited 2021 Aug 9]. Available from: agedcare.royalcommission.gov.au/sites/ default/files/2021-03/final-report-volume-1_0.pdf

14. House of Representatives Standing Committee on Health, Aged Care and Sport. Still waiting to be heard... report on the Inquiry into the Hearing Health and Wellbeing of Australia. Canberra: Commonwealth of Australia; 2017 [cited 2021 Aug 9]. Available from: parlinfo.aph.gov.au/ parllnfo/download/committees/reportrep/024048/toc_pdf/ Stillwaitingtobeheard....pdf;fileType=application\%2Fpdf

15. Community Affairs References Committee. Hear us: Inquiry into Hearing Health in Australia Canberra: Commonwealth of Australia; 2010 [cited 2021 Aug 9]. Available from: www.aph.gov.au/parliamentary_business/ committees/senate/community_affairs/completed_ inquiries/2008-10/hearing_health/report/index

16. Safe Work Australia. Managing noise and preventing hearing loss at work. Canberra: Safe Work Australia; 2020 [cited 2021 Aug 9]. Available from: www. safeworkaustralia.gov.au/sites/default/files/2020-07/ model_code_of_practice_managing_noise_and_ preventing_hearing_loss_at_work.pdf
17. Fuente A, McPherson B. Organic solvents and hearing loss: the challenge for audiology. Int J Audiol. 2006;45(7):367-81.

18. Lanvers-Kaminsky C, Zehnhoff-Dinnesen AA, Parfitt R, Ciarimboli G. Drug-induced ototoxicity: mechanisms, pharmacogenetics, and protective strategies. Clin Pharmacol Ther. 2017;101(4):491-500.

19. Hearing Health Sector Committee. Roadmap for hearing health. Canberra: Department of Health; 2019 [cited 2021 Aug 9]. Available from: www1.health.gov.au/internet/main/ publishing.nsf/Content/roadmap-for-hearing-health

20. Bright T, Pallawela D. Validated smartphone-based apps for ear and hearing assessments: a review. JMIR Rehabil Assist Technol. 2016;3(2):e13.

21. Oh YK, Ryu JK. Acoustic design guidelines for houses for hearing impaired seniors - in the framework of Korean building codes. Indoor Built Environ. 2018;29(3):343-54.

22. Smith JL, Mitchell P, Wang JJ, Leeder SR. A health policy for hearing impairment in older Australians: what should it include? Aust New Zealand Health Policy. 2005;2:1-7.

23. The Australian Competition and Consumer Commission. Issues around the sale of hearing aids: consumer and clinician perspectives. Canberra: ACCC; 2017 [cited 2021 Aug 9]. Available from: www.accc.gov.au/system/files/ Issues\%20around\%20the\%20sale\%20of\%20hearing\%20 aids\%20-\%20Consumer\%20and\%20clinical\%20 perspectives.pdf

\section{Copyright: (c) (i) (2) (2)}

(C) 2021 Kiely and Anstey. This article is licensed under the Creative Commons Attribution-NonCommercial-ShareAlike 4.0 International Licence, which allows others to redistribute, adapt and share this work non-commercially provided they attribute the work and any adapted version of it is distributed under the same Creative Commons licence terms. See: www.creativecommons.org/licenses/by-nc-sa/4.0/ 